\section{Chylolymphagioma of omentum presenting as a mesenteric cyst}

Omental cyst is a rare clinical entity and often poses a diagnostic challenge to the surgeon. The incidence is about 1 per 1,000,000 in adults and about 1 per 20,000 pediatric patients. ${ }^{1}$ These cases are mostly reported as incidental radiological findings and on laparotomy due to varied clinical presentation.

\section{Case Report}

A 35 year female patient presented with progressively enlarging lump in right side of abdomen with associated dull aching continuous pain, without radiation for 2 months. There were no associated gastrointestinal or urinary symptoms, weight loss or loss of appetite. Examination of the abdomen revealed $8 \times 8 \mathrm{~cm}$ intraabdominal lump palpable in the right lumbar region extending into right iliac fossa. The lump was non tender, with smooth surface and well defined margins. The swelling was mobile in vertical directions but side to side mobility was restricted. Ultrasonography of abdomen was reported to be normal.Contrast enhanced CT showed thin walled multi-septated cystic lesion with fluid attenuation in mesentry of small gut. CT findings suggestive of

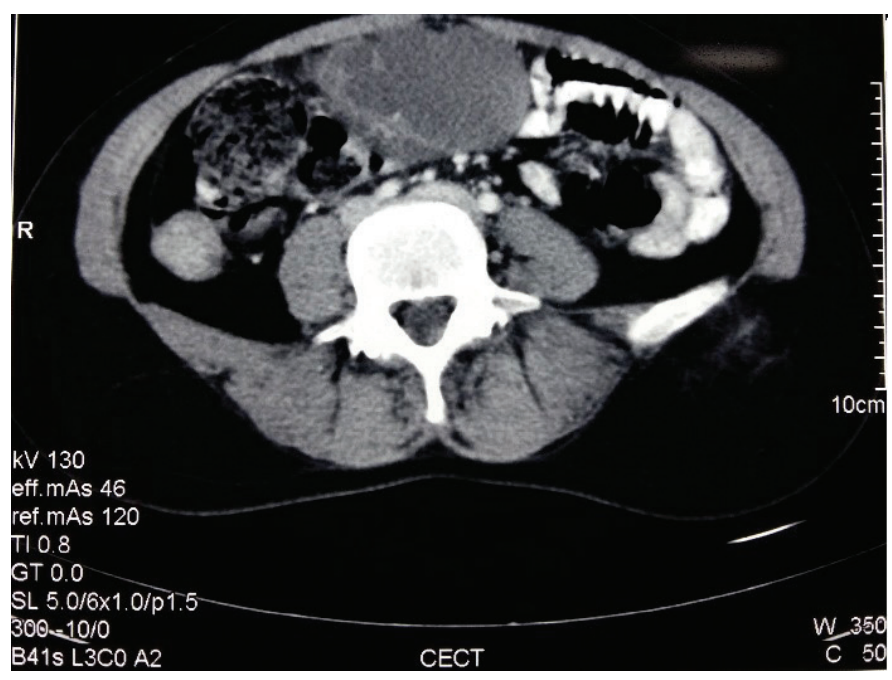

Figure 1: CECT abdomen showing multiloculated cystic mass in mid of the abdomen transverse section. mesenteric cyst. (Figure 1 and 2) Patient underwent exploratory laparotomy. On exploration a $15 \times 10 \mathrm{~cm}$ multi-cystic lesion was present in the greater omentum adhered to the greater curvature of stomach superiorly and transverse colon inferiorly. The cyst was removed en bloc by carefully separating the adjacent structure. The cyst was found to have dark hemorrhagic fluid (Figure 3). Abdomen was closed in layers. Patient postoperative period was unremarkable. Patient was discharged on 3rd post-operative day. Histological examination of the cyst showed chylolymphatic cyst. Patient remained well for 1 year of follow up.

\section{Discussion}

Omental cysts are confined to greater or lesser omentum. ${ }^{2}$ Most of the patients are asymptomatic with vague lump in abdomen. Others may present from vague abdomen pain with or without lump, intestinal volvulus, large lump mimicking ascites or as inguinal hernia. ${ }^{3}$ So far only 150 cases have been reported. Limited data is available on the etiopathogenesis of these cysts. Several theories have been put forward to explain the etiology. Since most of the cases presents in pediatric age group, congenital

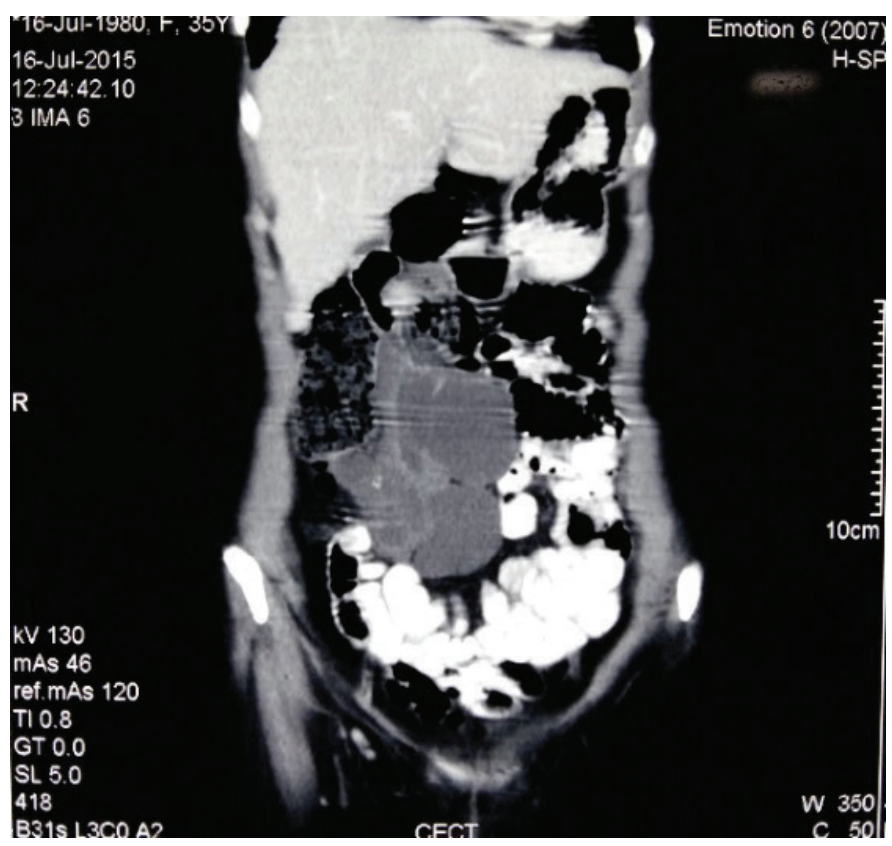

Figure 2: CECT abdomen showing multiloculated cystic mass in mid of the abdomen coronal view. 


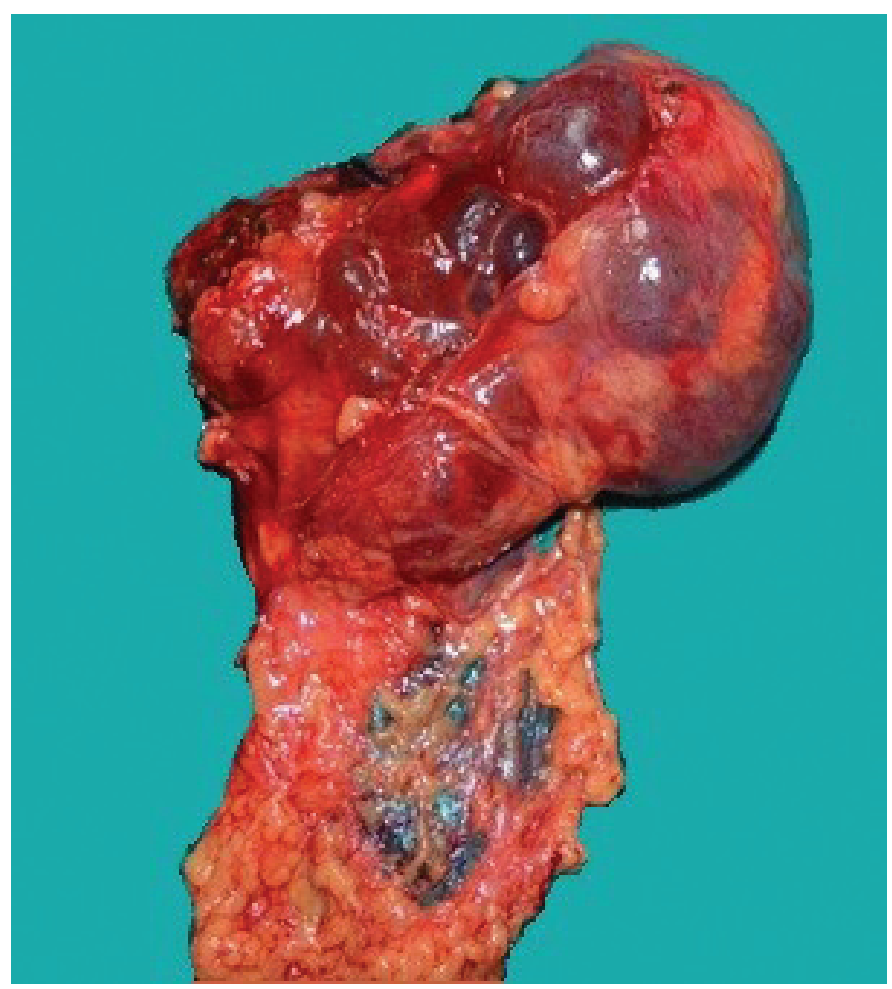

Figure 3: Excised specimen along with the part of the omentum.

abnormality of lymphatic drainage was thought to be most common cause. Other causes include trauma, neoplasm, and degeneration of lymph node. ${ }^{4}$ The cyst can be simple or multiple, unilocular or multilocular, content can be hemorrhagic, serous, chylous, or infected fluid. Histologically these are lined by endothelial cells and foam cells.

\section{SUDHIR KUMAR JAIN RONAL KORI VISHNURAJA RAJENDRAN ANKIT JAIN}

Department of Surgery, Maulana Azad Medical College, New Delhi-110002.

Correspondence: Ronal Kori Email: ronal_kori@yahoo.co.in
2. Ricketts RR. Mesenteric and omental cysts. Pediatric Surgery. 5th ed. 1998.1269-75

3. Lockhart C, Kennedy A, Ali S, et al. Mesenteric cysts: a rare cause of abdominal pain. Ulster Med J. 2005 May. 74(1):60-2.

4. Egozi El, Ricketts RR. Mesenteric and omental cysts in children. Am. Surg. 1997;63:287-90.

\section{References}

1. Theodoridis TD, Zepiridis L, Athanatos D, Tzevelekis F, Kellartzis D, Bontis JN. Laparoscopic management of mesenteric cyst: a case report. Cases J. 2009;2:132. 